\title{
Technological aspects of wear-resistant coating treatment on the surface of a cutting tool
}

\author{
A. E. Litvinov, Dr. Eng., Associate Prof., I. a. Head of Dept. of Surface Transport and Mechanics ${ }^{1}$, \\ e-mail: artstyleone@mail.ru \\ V. Yu. Buzko, Cand. Eng., Director of the Center of Prospective Technologies and Nanomaterials 1 \\ E. Yu. Balaev, Senior Lecturer, Dept. of Surface Transport and Mechanics ${ }^{1}$ \\ A. I. Goryachko, Engineer, Center of Prospective Technologies and Nanomaterials ${ }^{1}$
}

\section{${ }^{1}$ Kuban State Technological University, Krasnodar, Russia}

\begin{abstract}
The article presents a method for producing a nanostructured wear-resistant high-hardness coating with high physical, mechanical and strength characteristics, resistance to shock and vibration loads on the surface of spring-spring and tool steels used in the manufacture of cutting tools, including band saws. Technological modes were selected for the entire cycle of coating deposition of the developed compositions that have high adhesion to substrates made of steels of various grades, as well as provide high microhardness due to the nanostructure of the protective coating obtained on the surface. Studies are shown on the example of one of the most common methods of metal cutting cutting on band-cutting machines, using closed band saws as cutting tools made of spring-spring steels with obtained carbide cutting edges. Since in modern production, structural steels are replacing materials with high physical and mechanical characteristics (hardness, strength, etc.), the cutting process becomes much more complicated and imposes increased requirements on the cutting tool itself. To expand the range of materials to be processed, for which production use of band-cutting machines is possible, it became necessary to create a band saw with higher cutting characteristics. At the same time, the specificity of the operating conditions of the band saw shows that the blade should have such characteristics as increased vibration resistance, resistance to alternating and dynamic loads, and the cutting part of the saw should have increased resistance to shock, dynamic, alternating loads, have high hardness, as well as increased wear resistance. Therefore, one of the ways to solve this problem proposed in the article is to avoid the manufacture of band saws using the "bimetal" technology and use the same material as a tooth and a blade when applying a wear-resistant hard-alloy nanostructured coating on the surface of the cutting edge of the tooth. The practical usefulness of the developed protective nanostructured coatings for increasing the service life of carbide turning inserts is also shown.
\end{abstract}

Key words: high-temperature protection coating, wear resistance, heat resistance, high-speed tool steel, magnetron sputtering.

DOI: $10.17580 /$ cisisr.2021.02.21

\section{Introduction}

It is known that the idea of creating a layered nanocomposite from the highly hard phases $\mathrm{Al}_{2} \mathrm{O}_{3}, \mathrm{ZrN}, \mathrm{TiC}, \mathrm{Zr}(\mathrm{C}, \mathrm{N})$, $\mathrm{Ti}-\mathrm{Zr}-\mathrm{C}, \mathrm{TiB}_{2}$ is one of the recognized directions for solving the problem of thermomechanical wear of metalworking tools [1-4]. Thus, laminated composite materials have shown themselves to be efficient under complex loading conditions on other mechanical engineering products [3-7] and have firmly strengthened their positions in production. With a correct analysis of the operating conditions of the product, whether it is a part or a cutting tool, in particular a band saw blade, it can be found that this or that zone or layer can work for a specific type of loading. Consequently, it can be made from a material with characteristics that meet the given loading conditions. Thus, based on the analysis of the loading conditions during the operation of the band saw blade, the idea of a bimetallic saw was proposed, which is the correct way to solve the arising problem, but the main disadvantage is the presence of a welded joint sensitive to vibration, dynamic and shock loads, as well as the difficulty of obtaining a defect-free welded seam, which is also complicated by the criterion of weldability of many materials with each other and in general. An alternative can be the application of a coating on their surface of saw tooth by the method of ion-magnetron sputtering, which allows to significantly change the physical and mechanical characteristics of the material of the cutting edge of the teeth (which will be the material of the entire band saw blade - spring steel). At the same time, the output is a layered composite with high adhesion, comparable in value to the metallurgical one. Obtaining a coating by ion-magnetron sputtering, which allows spraying thin films and is currently the most optimal technology for obtaining coatings on cutting tools, both in terms of adhesion and the resulting structure of the sprayed nanostructured coating [4].

\section{Materials and Equipment}

For the research, the following equipment was used: a JET band saw (testing the obtained saws under conditions close to factory conditions), a Falcon 500 micro hardness meter (micro hardness tests for preliminary analysis of wear

(c) Litvinov A. E., Buzko V. Yu., Balaev E. Yu., Goryachio A. I., 202 
resistance), an Instron 8801 testing machine (fatigue test), installation of a magnetron radio frequency spraying Q150T ES (coating process), scanning electron microscope "JEOL JSM-7500F" (studying the microstructure of coatings), Bruker Vertex 70 FTIR IR spectrometer (for analyzing the composition of coatings), TR100 Surface Roughness Tester (for roughness measurements).

\section{Analysis of Simulation Results and Experimental Data}

To apply nanostructured and wear-resistant high-hard coatings by magnetron sputtering on the surface of cutting tools, a sequential technological cycle is used in the work, which includes:

1) Preliminary etching of the product surface with lowtemperature argon plasma to improve the adhesion of the applied protective coating;

2) Application by the method of magnetron-plasma spraying of a nanostructured film of metal or alloy on the surface of the product;

3) Thermal oxidative phase-forming annealing for the appearance of nanoparticles of high-hard oxides of a cubic system (aluminum or chromium oxides) and nanoparticles of medium-hard oxides (oxides of titanium, niobium, vanadium), which also leads to an increase in the adhesion of the protective coating, an increase in hardness, wear resistance and fatigue strength due to the recrystallization process applied coating.

Processing the surface of the cutting tool with low-temperature argon plasma makes it easy to clean the surface of the product from dirt and grease residues. At the same time, argon ion-plasma etching (surface ablation of the substrate material) occurs, which makes it possible to change the structural and mechanical properties of the product, increase the roughness, which will improve the adhesion between the metal surface of the cutting tool and the applied material. Plasma treatment can be applied to a wide range of cutting tools of any composition and complex geometries.

With the help of magnetron-plasma spraying, nanostructured metal thin-layer films of the desired chemical composition and thickness are deposited. With the method of obtaining the coating, no thermal heating of the cutting tool occurs, due to which there is no occurrence of residual stresses on the surface of the tool and along the product-coating interface. In turn, the resistance of the coated cutting tool to fatigue cracking is improved. Also, ion-plasma spraying occurring at room temperature provides a coating having a nanoscale structure in the size range of $5-15 \mathrm{~nm}$. Thin nanostructured coatings, with a certain crystal structure (cubic and tetragonal syngonies) and size of nanoparticles (belonging to the region of maximum realization of the Hall-Petch effect), show ultra-high hardness, high fatigue strength, and increased wear resistance.

The TiAlVW composition used in our study has high physical and mechanical properties due to the fact that the alternation of lamellae of the $\alpha 2$-phase and $\gamma$-phase of the titanium-aluminum intermetallic compound is provided. At the same time, alloying with vanadium and tungsten makes it possible to increase the heat resistance of the material, hardness, with a decrease in the thickness of the lamellas of alternating $\alpha 2$-phase and $\gamma$-phase, which additionally makes it possible to increase the physical and mechanical properties of the coating of this composition and, as a consequence, the operational characteristics of the cutting tool.

Thermal oxidative phase-forming annealing makes it possible to create a surface layer of highly hard, highly thermally stable cubic or tetragonal phase oxide nanoparticles on the surface of a metal adhesive film, which leads to the production of highly hard coatings with high wear resistance and significant fatigue strength.

The method of applying nanostructured and wearresistant coatings with high adhesion to the surface of the cutting tool at the first stage, the surface of the product is preliminarily etched with low-temperature argon plasma to improve the adhesion of the applied protective coating in a vacuum chamber with accelerated ions at a pressure of $1-3 \mathrm{~Pa}$, after which it is applied by magnetron-plasma spraying nanostructured film of TiAlVW alloy with the following weight \% ratio: Al 5.2-6.4; V 3.7-4.2; W 1.4-2; $\mathrm{Ti}$ - the rest, by transferring from the target surface a composition similar to the coating applied to the surface of the cutting tool, after which thermal oxidative phase-forming annealing is carried out at a temperature of $550-650^{\circ} \mathrm{C}$ for 1-2 hours for the appearance of nanoparticles of high-hard oxides of a cubic system (oxides of aluminum, chromium, titanium, etc.), which also leads to an increase in the adhesion of the protective coating, an increase in hardness, wear resistance and fatigue strength due to the process of recrystallization of the applied coating.

As a proof of concept of the proposed project, studies of the hardness of nanostructured metal coatings with nanoparticles of organized high-strength oxide films of cubic or tetragonal phases on the surface of high-speed steel tools (metal cutting saw and metal-ceramic carbide cutters) were carried out.

For the deposition of nanostructured coatings $100 \mathrm{~nm}$ thick on the surface of the cutting edge of HSS band saw or VNMG160404-PM type diamond carbide turning inserts (Zhuzhou Jintai Cemented Carbide Co., Ltd., WC-8\% Co) without protective coatings a Q150T ES RF magnetron sputtering unit with appropriate metal targets was used. The following values of magnetron sputtering currents were used: $120 \mathrm{~mA}$ for Ti6Al4VW alloy, $80 \mathrm{~mA}$ for Kh15N60 nichrome, $120 \mathrm{~mA}$ for aluminum, and $50 \mathrm{~mA}$ for chromium. A produced nanosized aluminum film was annealed at a temperature of $600{ }^{\circ} \mathrm{C}$ to convert it to the cubic oxide phase. The rest of the alloys were not modified by annealing, but according to IR spectroscopy data, oxide phases were present in them in a small amount due to the used method of magnetron sputtering at weak discharge $\left(10^{-4} \mathrm{~Pa}\right)$ in argon plasma with air oxygen impurities.

The microstructure of the obtained coatings on the saw teeth was studied using a JEOL JSM7500F scanning electron microscope and shown in Fig. 1.

According to electron microscopy data, the nanostructured coating of thermally oxidized aluminum $\left(\mathrm{Al}_{2} \mathrm{O}_{3}\right)$ 
exhibits the highest microroughness. It can be seen that the fabricated coatings contain clusters of nanoparticles $10-45 \mathrm{~nm}$ in size. In this case, the size of clusters of nanoparticles in different coatings is different. The size distribution of nanoparticles in derived coatings is shown

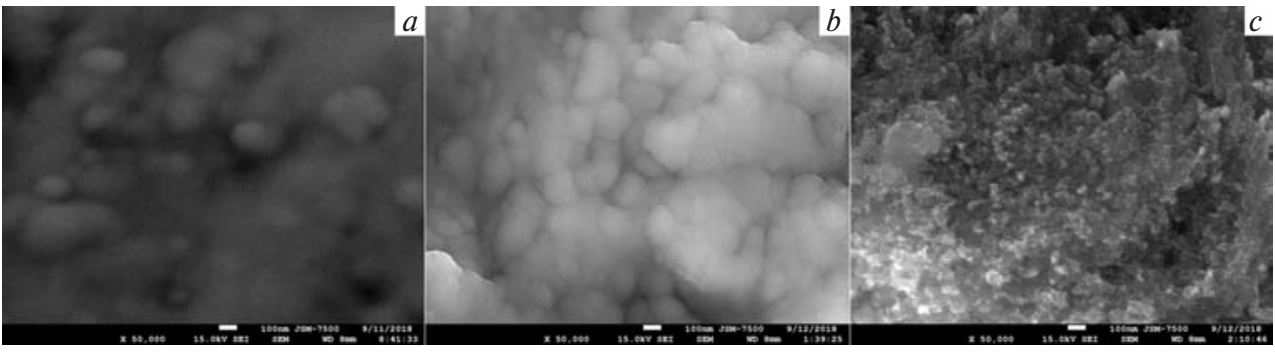

Fig. 1. Microstructure of the obtained coatings: $a-$ nichrome Kh15N60; $b-$ Ti6Al4VW alloy; $c$ - thermally oxidized aluminum $\left(\mathrm{Al}_{2} \mathrm{O}_{3}\right)$

in Fig. 2.

The size distribution of nanoparticles in the coating based on the Ti6Al4VW alloy is close to unimodal, and for the coating based on nichrome Kh15N60 and chromium it is bimodal. The bimodal distribution of nanoparticles in a coating deposited by magnetron sputtering is associated with the processes of recrystallization of nanoparticles. The nanostructured $\mathrm{Al}_{2} \mathrm{O}_{3}$ coating shows a wide-range distribution of nanoparticles in size, which is characteristic of secondary crystallization processes due to the oxidation of metal nanoparticles with remelting and coalescence $[8,9]$ due to the low values of the enthalpy of fusion characteristic of small aluminum nanoparticles.

The weighted average calculated size of nanoparticles in the applied nanostructured coatings is presented in Table $\mathbf{1}$.

It can be assumed that, in accordance with the wellknown Hall-Petch equation [10], the size of the nanoparticles of the deposited alloy films and the resulting aluminum oxide is close to the transition boundary from the forward Hall-Petch law to the reverse one [11-13]. Thus, a high microhardness can be expected from the obtained nanostructured coatings. For chromium coating it can be expected, that size of produced nanoparticles is smaller than transition from Hall-Petch region to inverse Hall-Petch range.

The Rockwell microhardness of the obtained coating samples on the band sew teeth was measured on a Falkon 500 microhardness tester and microhardness values were taken as averages over the results of 10 measurements (Table 2).

From the data in Table 2, it follows that, with the exception of the chromium film, the nanostructured coatings used noticeably increase the hardness of the working surfaces of the HSS saw teeth. In the case of a chromium film, it can be assumed that the small size of chromium nanoparticles, characteristic of the region with the manifestation of the inverse Hall-Petch effect, leads to the formation of an amorphous film coating with low microhardness.

The Vickers microhardness for the cutting inserts studied by us on the cutting edge line was determined in a standard way using a Falcon 500 microhardness tester and the corresponding software according to the results of 5 independent measurements (Table 3) for two investigated samples of cutting inserts with and without coatings (a total of 10 measurements of microhardness values for each modifying sample coverage).

From the data in Table 3 it follows that, with the exception of nichrome film, the coatings used noticeably increase the hardness of the working surfaces of the cutting edge of

carbide cutting inserts. For the case of a nanostructured film coating of $\mathrm{Al}_{2} \mathrm{O}_{3}$ obtained by thermal oxidation of aluminum, high hardness is quite expected, since according to the data of [14], oxidation of metallic aluminum in air above $5000{ }^{\circ} \mathrm{C}$ produces a film of the cubic spinel phase $\gamma-\mathrm{Al}_{2} \mathrm{O}_{3}$ with a high microhardness up to $\sim 19 \mathrm{GPa}$ [15]. In the case of the formation of the hexagonal $\alpha$-phase of $\mathrm{Al}_{2} \mathrm{O}_{3}$ in the film, the it microhardness will also be significant and can be up to $23.5 \mathrm{GPa}$ [16]. In the case of the prepared coating of the Ti6Al4VW alloy, the obtained considerable microhardness result is rather unexpected. Nevertheless,

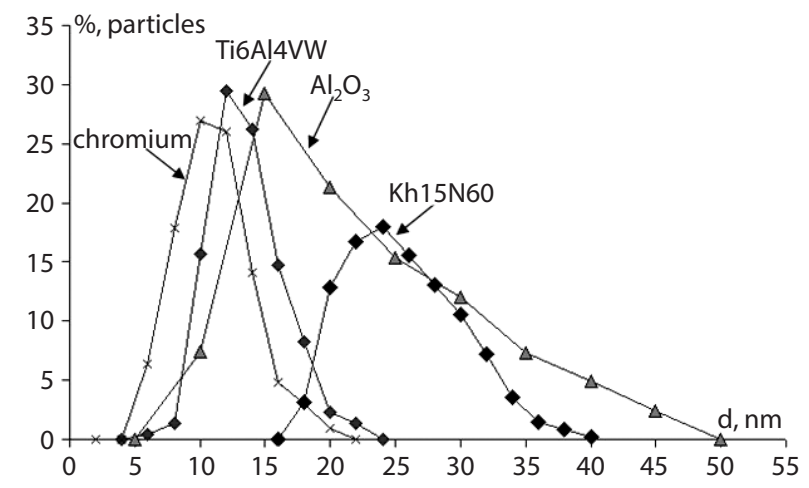

Fig. 2. Size distribution of nanoparticles in derived coatings

Table 1. Average size of nanoparticles ( $\mathrm{nm}$ ) in applied nanostructured coatings

\begin{tabular}{|c|c|c|c|}
\hline Chromium & $\mathrm{Al}_{2} \mathrm{O}_{3}$ & Kh15N60 & Ti6Al4VW \\
\hline $11 \pm 3$ & $23 \pm 9$ & $26 \pm 6$ & $14 \pm 4$ \\
\hline
\end{tabular}

\begin{tabular}{|}
\hline \multicolumn{5}{|c|}{$\begin{array}{l}\text { Table 2. Rockwell microhardness (GPa) of samples of the initial } \\
\text { material of saw teeth and with applied nanostructured coatings }\end{array}$} \\
\hline $\begin{array}{c}\text { Saw tooth } \\
\text { material }\end{array}$ & Chromium & $\mathrm{Al}_{2} \mathrm{O}_{3}$ & Kh15N60 & Ti6Al4VW \\
\hline $54 \pm 2$ & $55 \pm 6$ & $70 \pm 1$ & $62 \pm 2$ & $73 \pm 2$ \\
\hline
\end{tabular}

Table 3. Vickers microhardness (GPa) of samples of the initial material of the cutting edge of carbide inserts and with applied nanostructured coatings

\begin{tabular}{|c|c|c|c|}
\hline $\begin{array}{c}\text { Cutter edge } \\
\text { material }\end{array}$ & $\mathrm{Al}_{2} \mathrm{O}_{3}$ & Kh15N60 & Ti6Al4VW \\
\hline $1770 \pm 100$ & $2030 \pm 140$ & $1530 \pm 105$ & $1954 \pm 108$ \\
\hline
\end{tabular}


according to the data of studies, a decrease in the grain size in the Ti6Al4V alloy [17, 18] leads to a strong increase in its strength and plasticity, and it was recently shown in [19] that the Ti6Al4V alloy nanostructured by laser sintering has a nanohardness of $7.43 \mathrm{GPa}$. Also, one should take into account the possibility of the formation of a certain fraction of the high-hard TiN phase when using the magnetron sputtering method at a weak discharge $\left(2 \cdot 10^{-3}\right.$ mbar $)$ in an argon plasma with air nitrogen impurities. As shown in [20], the formation of a cubic high-hardness TiN phase on the surface of the Ti6Al4V alloy leads to a significant increase in its microhardness.

Thus, the preliminary results show the validity of the proposed approach, since the developed single-layer nanostructured coatings noticeably increase the hardness of the working surfaces of tools made of high speed steel and carbide composition WC-8\% Co.

Next, the preparation of a combined wear-resistant coating for a cutting tool in the form of HSS band saws and carbide cutting inserts was considered. The wearresistant protective coating was applied as follows. At the first stage, the surface of the protected item was pre-etched with a low-temperature argon plasma to improve the adhesion of the applied protective coating in a vacuum chamber with accelerated ions at a pressure of $1-3 \mathrm{~Pa}$. Next, a nanostructured film of the composition TiAlVNbB was deposited by the method of radio-frequency magnetron-plasma spraying by spraying a combined target made of TiAlVNb alloy with a small proportion of pressed TiB2 micropowder at the following weight $\%$ ratio: Al 5.5-6.5; V 7-8; Nb 2-4; $\mathrm{TiB}_{2} 1-2 ; \mathrm{Ti}$ - rest (compositions are indicated in Table 3), by transferring from the target surface a composition similar to the coating applied to the surface of the cutting tool. After deposition of the protective film, thermal oxidative phase-forming anneal-

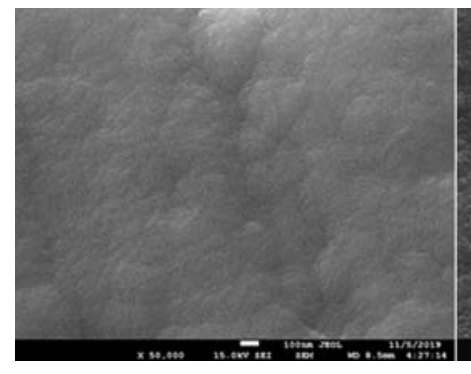

ing was carried out in air at temperatures from 550 to $650{ }^{\circ} \mathrm{C}$ for 1 hour for the appearance of highly hard $\gamma-\mathrm{Al}_{2} \mathrm{O}_{3}$ nanoparticles of cubic syngony with admixtures of the phases of oxide nanoparticles $\mathrm{TiO}_{2}, \mathrm{VO}_{2}$ and $\mathrm{Nb}_{2} \mathrm{O}_{5}$, which also leads to an increase in the adhesion of the protective coating, an increase in hardness [21], wear resistance, corrosion resistance [22] and fatigue strength due to the process of recrystallization of the applied coating.

The microstructure of samples of the obtained protective coatings before and after thermal phase-forming annealing is shown in Fig. 3 and 4. According to these figures, in the course of thermal annealing, a pronounced change in the microstructure of magnetron-sputtered protective cermet coatings occurs both from the oxidation of metal nanoparticles according to IR spectroscopy data and due to recrystallization of the formed oxide phases. In all cases studied

\begin{tabular}{|c|c|c|c|c|c|}
\hline Sample & $\begin{array}{c}\text { Composition, } \\
\%\end{array}$ & $\begin{array}{l}\text { Plasma etching } \\
\text { pressure, } \mathrm{Pa}\end{array}$ & $\begin{array}{c}\text { Annealing } \\
\text { temperature / } \\
\text { time, }{ }^{\circ} \mathrm{C} / \text { hour }\end{array}$ & $\begin{array}{c}\text { Treatment } \\
\text { resistance for } \\
\text { 30KhGSA, min. }\end{array}$ & $\begin{array}{c}\text { Microhardness, } \\
\text { GPa }\end{array}$ \\
\hline Example 1 & $\begin{array}{c}\text { Al 5.5; V 7.0; Nb 2.0; } \\
\mathrm{TiB}_{2} 1.0 ; \mathrm{Ti} \text { - rest }\end{array}$ & 3 & $550 / 1$ & $83 \pm 1$ & 47.3 \\
\hline Example 2 & $\begin{array}{c}\text { Al 6.0; V 7.5; Nb 3.0; } \\
\mathrm{TiB}_{2} 1.5 ; \mathrm{Ti} \text { - rest }\end{array}$ & 2 & $600 / 1,5$ & $86 \pm 2$ & 47.9 \\
\hline Example 3 & $\begin{array}{c}\text { Al 6.5; V 8.0; Nb 4.0; } \\
\mathrm{TiB}_{2} 2.0 ; \mathrm{Ti} \text { - rest }\end{array}$ & 1 & $650 / 2$ & $89 \pm 1$ & 49.2 \\
\hline Prototype & - & - & - & $81 \pm 1$ & 46.7 \\
\hline
\end{tabular}

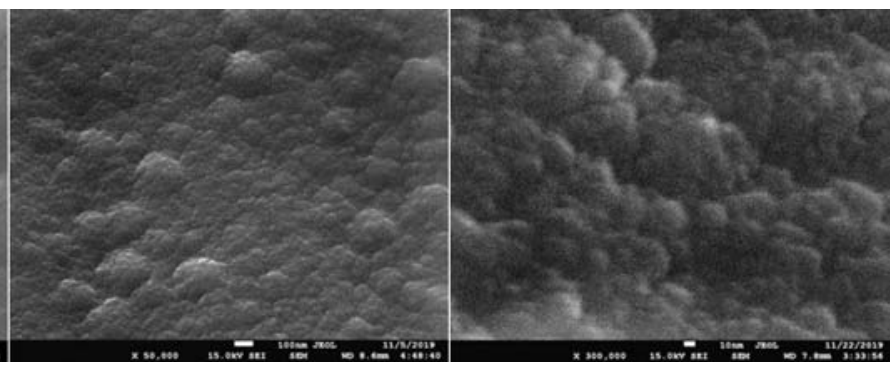

b
Fig. 3. Microstructure of the obtained protective coating of composition $\left(\mathrm{Ti}_{76.10} \mathrm{Al}_{8.89} \mathrm{~V}_{5.99} \mathrm{Nb}_{0.94} \mathrm{~B}_{8.07}\right)_{\mathrm{x}} \mathrm{O}_{\mathrm{y}}$ (example 1): $a$ - before thermal annealing; $b$ - after thermal annealing; $c$ - after thermal annealing at high magnification

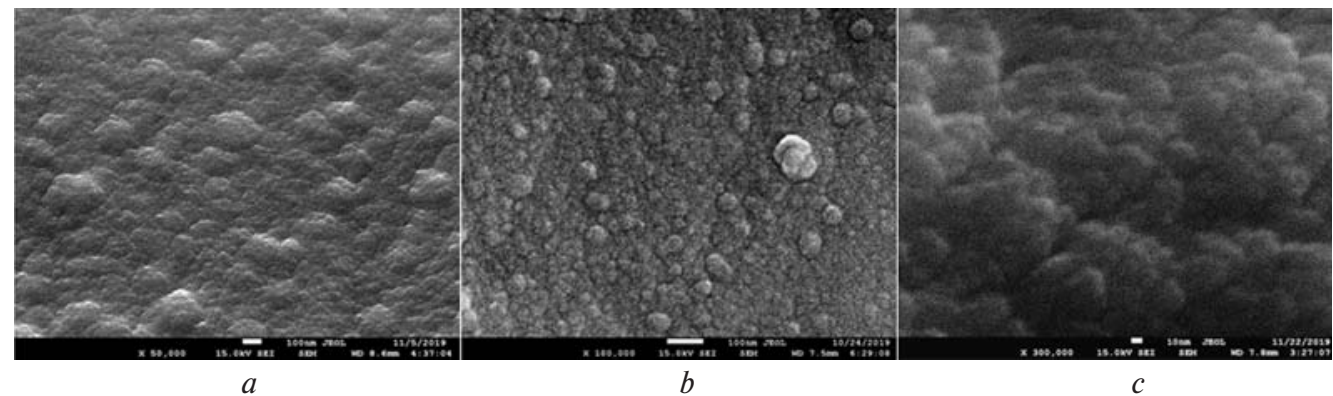

Fig. 4. The microstructure of the obtained protective coating of composition $\left(\mathrm{Ti}_{70.63} \mathrm{Al}_{10.51} \mathrm{~V}_{6.85} \mathrm{Nb}_{1.88} \mathrm{~B}_{16.14}\right)_{\mathrm{x}} \mathrm{O}_{\mathrm{y}}$ (example 3): $a$ - before thermal annealing; $b$ - after thermal annealing; $c$ - after thermal annealing at high magnification 
by us, the obtained samples of oxide protective coatings are nanostructured with a nanoparticle size from 15 to $30 \mathrm{~nm}$.

It is known that during thermal oxidation of titanium alloys, according to X-ray photoelectron spectroscopy data [23], amorphous oxide films of three types of titanium oxide phases $\mathrm{TiO}, \mathrm{Ti}_{2} \mathrm{O}_{3}$, and $\mathrm{TiO}_{2}$ are formed on the surface. Under our conditions of prolonged thermal oxidative annealing, the expected main phase in the obtained coatings is $\mathrm{TiO}_{2}$. It is known that the main crystalline phases of $\mathrm{TiO}_{2}$ are tetragonal anatase and rutile phases. At low-temperature oxidation up to $400{ }^{\circ} \mathrm{C}$, the anatase phase predominates, and at temperatures above $600{ }^{\circ} \mathrm{C}$ anatase is almost completely transformed into a thermodynamically more stable and harder [24] rutile phase. Based on the thermal annealing conditions we used, it can be assumed that the basis of the created nanostructured wear-resistant high-hard protective coatings is a film of medium-hard rutile nanoparticles interspersed with high-hard nanoparticles of the cubic phase $\gamma-\mathrm{Al}_{2} \mathrm{O}_{3}, \mathrm{TiB}_{2}$, the pseudohexagonal phase of the tetrahedral phase of the $\mathrm{Nb}_{2} \mathrm{O}_{5}$ medium-hard phase [25].

Tests of the manufactured protective coatings on commercial carbide cutting inserts of the VNMG160404-PM type were carried out by orthogonal turning of cylindrical parts with a diameter of $20 \mathrm{~mm}$ and a length of $200 \mathrm{~mm}$ from structural alloy steel $30 \mathrm{KhGSA}$ in the form of a bar with an initial diameter of $22 \mathrm{~mm}$ with the following parameters of turning 30HGSA steel: $V$ (cutting speed) $=80 \mathrm{~m} / \mathrm{min}$, $s$ (feed) $=$ from 0.2 (initial stage of turning) to 0.1 (final treatment) $\mathrm{mm} / \mathrm{rev} ; t$ (depth of cut) $=0.5 \mathrm{~mm}$. We determined the wear criterion of the cutting inserts by the quality of the processed surface, namely, the required level of roughness of the processed cylindrical surface of steel $30 \mathrm{HGSA}$ at the level of $\mathrm{Ra} \leq 2.5 \mu \mathrm{m}$ in accordance with measurements with a digital profilometer TR100. The service life of carbide cutters with developed protective nanostructured coating when turning a cylindrical part made of steel 30HGSA was estimated by averaging over five time measurements and. the test results are shown in Table 4. Thus, the wear of cutting inserts that did not provide the required roughness were considered outside the service life for a particular production with the required turning parameters.

Analysis of the data presented in the Table 3 allows us to conclude that cutting carbide inserts with prepared wearresistant nanostructured coatings obtained by the above method are characterized by higher physical and mechanical characteristics and a longer service life (up to $10 \%$ of the time when turning steel 30HGSA), compared with cutting plates of metal-ceramic cutters made according to previously known methods.

The reasons for this may be the complex cooperative nature of interparticle and interphase interactions in the created protective film coatings. Thus, for example, upon oxidative phase-forming annealing in air in nanostructured TiAlVNbB films, in addition to nanoparticles of various $\mathrm{Al}_{2} \mathrm{O}_{3}$ phases, nanoparticles of titanium, vanadium, and niobium oxides with various combinations of microhardness and plasticity can be formed.

\section{Conclusion}

As a result of the research, a method was developed for obtaining a wear-resistant coating for a cutting tool, including the application of a magnetron sputter coating on the surface of a cutting tool based on an alloy of titanium, aluminum and niobium with small additions of titanium diboride. Obtaining a coating on the surface of the cutting tool (HHS band saws and carbide cutting inserts) is carried out by the method of magnetron-plasma sputtering, including preliminary plasma etching of the surface of the cutting tool in a vacuum chamber with accelerated argon ions, followed phase-forming thermal oxidative annealing to derived films of high-hard nanoparticles of $\mathrm{Al}_{2} \mathrm{O}_{3}$, titanium/vanadium/ niobium oxides and borides.

\section{Acknowledgment \\ The work was supported by the Council on grants of the President of the Russian Federation (Agreement CII- 399.2019.1)}

\section{REFERENCES}

1. Kiselev S. V., Blakhin A. V., Dulevich A. F. Band saws with high durability. Aktualnye problemy lesnogo kompleksa, 2016. No. 46. pp. 153-155.

2. Litvinov A. E. Improving tool life and machining precision in band saws. Russian Engineering Research. 2016. Vol. 36. pp. 760-761. DOI: $10.3103 / \mathrm{S} 1068798 X 16090124$.

3. Blednova Z. M., Rusinov P. O., Balaev E. U. Quantification of hereditary regularities of surface layer formation and transformation made of multicomponent shape memory materials in a high-energy impact. Materials Today: Proceedings. 2017. pp. 4652-4657. DOI: 10.1016/j.matpr.2017.04.046.

4. Litvinov A. E., Buzko V. U., Balaev E. Yu., Goryachko A. I. Development of a method of applying nanostructured and wear-resistant coatings with high adhesion to the surface of the cutting tool. IOP Conference Series: Materials Science and Engineering. 2019. p. 012187.

5. Hasui A., Morigaki O, Surfacing and spraying. Moscow. Mashinostroenie. 1985. 240 p.

6. Karas Yu. A., Karacheva G. A. Implementation of the technology of applying wear-resistant hardening coatings to special cutting tools. Aktualnye problemy aviatsii i kosmonavtiki. 2013. No 2. pp. 25-26.

7. Rublevskaja E. V., Komarova P. A., Shcherbakova A. V., Husnutdinov T. D., Ramenskaja E. V. Analysis of parameters of cutting process by band saws. Aktualnye problemy aviatsii i kosmonavtiki. 2017. № 1. pp. 35-36

8. Sun J., Simon S. L. The melting behavior of aluminum nanoparticles. Thermochimica Acta. 2007. Vol. 463. pp. 32-40.

9. Bhatt S., Kumar M. Effect of size and shape on melting and superheating of free standing and embedded nanoparticles. Journal of Physics and Chemistry of Solids. 2017. Vol. 106. pp. 112-117.

10. Cordero Z. C., Knight B. E., Schuh C. A. Six decades of the HallPetch effect - a survey of grain-size strengthening studies on pure metals. International Materials Reviews. 2016. Vol. 61. No. 8. pp. $495-512$.

11. Dunstan D. J., Bushby A. J. Grain size dependence of the strength of metals: the Hall-Petch effect does not scale as the inverse square root of grain size. International Journal of Plasticity. 2014. Vol. 53. pp. 56-65.

12. Davila L. P., Xu W. Tensile nanomechanics and the Hall-Petch effect in nanocrystalline aluminium. Materials Science \& Engineering $A$. 2018. Vol. 710. pp. 413-418.

13. Naik S. N., Walley S. M. The Hall-Petch and inverse Hall-Petch relations and the hardness of nanocrystalline metals. Journal of Material Science. 2020. Vol. 55. pp. 2661-2681. 
14. Jeurgens L. P. H., Sloof W. G., Tichelaar F. D., Mittemeijer E. J. Structure and morphology of aluminium-oxide films formed by thermal oxidation of aluminium. Thin Solid Films. 2002. Vol. 418. pp. 89-101.

15. Zywitzki O., Hoetzsch G. Influence of coating parameters on the structure and properties of $\mathrm{Al}_{2} \mathrm{O}_{3}$ layers reactively deposited by means of pulsed magnetron sputtering. Surface \& Coatings Technology. 1996. Vol. 86-87. pp. 640-647.

16. Cheng Y., Chu C., Zhou P. Effects of corundum-structured seeds on the low-temperature growth and hardness of the aluminabased films. Materials Research Express. 2020. No. 7. p. 076401.

17. Akram J., Pal D., Stucker B. Establishing Flow Stress and Elongation Relationships as a Function of Microstructural Features of Ti6Al4V Alloy Processed using SLM. Designs, 2019. No. 3. p. 21.

18. Chong Y., Deng G., Gao S. et al. Yielding nature and Hall-Petch relationships in Ti-6Al-4V alloy with fully equiaxed and bimodal microstructures. Scripta Materialia. 2019. Vol. 172. pp. 77-82.

19. Li Y., Song L., Xie P. et al. Enhancing Hardness and Wear Performance of Laser Additive Manufactured Ti6Al4V Alloy Through Achieving Ultrafine Microstructure. Materials. 2020. Vol. 13 (5), p. 1210.
20. Pi Y., Agoda-Tandjawa G., Potiron S. et al. Surface Nanocrystallization of Ti-6Al-4V Alloy: Microstructural and Mechanical Characterization. Journal of Nanoscience and Nanotechnology. 2012. Vol. 12. pp. 4892-4897.

21. Kalisz M., Grobelny M., Mazur M. et al. Mechanical and electrochemical properties of $\mathrm{Nb}_{2} \mathrm{O}_{5}, \mathrm{Nb}_{2} \mathrm{O}_{5}: \mathrm{Cu}$ and graphene layers deposited on titanium alloy (Ti6Al4V). Surface \& Coatings Technology. 2015. Vol. 271. pp. 92-99.

22. Gan L., Gomez R. D., Castillo A. et al. Ultra-thin aluminum oxide as a thermal oxidation barrier on metal films. Thin Solid Films. 2002. Vol. 415. pp. 219-223.

23. Pouilleau J., Devilliers D., Garrido F. et al. Structure and composition of passive titanium oxide films. Materials Science and Engineering B. 1997. Vol. 47. pp. 235-243.

24. Vasantha Kumar C. A., Rajadurai J. S. Influence of rutile $\left(\mathrm{TiO}_{2}\right)$ content on wear and microhardness characteristics of aluminium-based hybrid composites synthesized by powder metallurgy. Transactions of Nonferrous Metals Society of China. 2016. Vol. 26. Iss. 1. pp. 63-73.

25. Liao J., Tan R., Kuang Z. et al. Controlling the morphology, size and phase of $\mathrm{Nb}_{2} \mathrm{O}_{5}$ crystals for high electrochemical performance. Chinese Chemical Letters, 2018, Vol. 29, No. 12. pp. 1785-1790. 